\title{
EFEKTIFITAS GAMIFIKASI DALAM PEMBELAJARAN MATEMATIKA
}

\author{
Oleh: \\ Nurjannah ${ }^{1)}$, Andi Baso Kaswar ${ }^{2)}$, Eman Wahyudi Kasim ${ }^{\text {3) }}$ \\ ${ }^{1}$ Institut Agama Islam Muhammadiyah Sinjai \\ ${ }^{2}$ Universitas Negeri Makassar \\ ${ }^{3}$ Institut Agama Islam Negeri Ambon \\ Email: nurjannah310807@gmail.com
}

\begin{abstract}
Abstrak
Penelitian ini merupakan penelitian eksperimen dengan menggunakan True Experimental Design dengan pretest dan posttest. Penelitian ini bertujuan untuk melihat keefektifan penggunaan gamifikasi pada pembelajaran matematika. Gamifikasi yang dimaksud pada penelitian ini adalah aplikasi Kahoot! dan Quizizz. Penelitian ini dilakukan di SMP Negeri 2 Kahu. Adapun sampel pada penelitian ini sebanyak 27 siswa kelas VIIIB. Teknik analisis data dilakukan dengan menggunakan uji paired sample t-test. Akan tetapi, sebelum itu, dilakukan uji normalitas terhadap data penelitian. Hasil uji normalitas menunjukkan bahwa nilai Asymp Sig. (2-tailed) sebesar 0,200 lebih besar dari 0,05 yang mengartikan bahwa data berdistribusi normal. Sedangkan hasil uji paired sample t-test diperoleh nilai signifikansi sebesar 0,000 dimana nilai ini kurang dari 0,05. Sehingga, berdasarkan kaidah pengambilan keputusan diperoleh bahwa terdapat perbedaan hasil belajar sebelum dan sesudah dilakukannya gamifikasi. Dengan kata lain, pemberian gamifikasi efektif dalam pembelajaran matematika.
\end{abstract}

Kata kunci-gamifikasi, Kahoot!, Quizizz

\section{Abstract}

This research was an experimental research using True Experimental Design with pretest and posttest. This study aims to see the effectiveness of the use of gamification in mathematics learning. The gamification referred to in this study are Kahoot! and Quizizz. This research was conducted at SMP Negeri 2 Kahu. The samples in this study were 27 students of class VIIIB. The data analysis technique was performed using paired sample t-test. However, before that, a normality test was carried out on the research data. The results of the normality test show that the Asymp Sig. (2-tailed) of 0.200 greater than 0.05, which means that the data is normally distributed. While the results of the paired sample t-test obtained a significance value of 0.000 where this value is less than 0.05. So, based on the rules of decision making, it is found that there are differences in learning outcomes before and after gamification. In other words, giving gamification is effective in learning mathematics.

Keywords—gamification, Kahoot!, Quizizz

\section{PENDAHULUAN}

Pendidikan adalah kunci untuk semua kemajuan dan pengembangan kualitas, sebab dengan pendidikan generasi muda dapat menyadari semua potensinya. Oleh karena itu peran guru sangat besar dalam meningkatkan kualitas pendidikan. Guru di era milenial, mereka dituntut lebih inovatif sehingga bisa bersinergi dengan kemajuan teknologi di Indonesia bidang pendidikan (Darmawiguna, et.al, 2019).

Perkembangan teknologi berdampak tidak hanya pada gaya hidup terhubung tetapi juga dunia pendidikan. Sektor pendidikan perlu mengimbangi kemajuan teknologi dengan mengintegrasikannya ke dalam sistem pendidikan. Sekolah-sekolah di Indonesia diharapkan mampu menerapkan sistem pembelajaran yang mendukung revolusi industri 4.0 seperti yang dicanangkan oleh pemerintah Indonesia. Ini hanya bisa dilakukan jika sekolah dan guru melek teknologi (Nugroho, et.al, 2019).

Seiring dengan perkembangan ilmu pengetahuan dan teknologi guru dituntut dalam menjalankan tugasnya adaptif, inovatif, kreatif dan kritis dalam proses pembelajaran (Hasan, 2019). Adaptif artinya menyesuaikan dengan situasi saat ini. Kemajuan dan perkembangan pembelajaran terus bergerak secara eksponensial mengikuti perubahan peradaban teknologi, dari alat dan media, materi, kompetensi yang ingin dicapai sesuai dengan kurikulum yang berlaku. Inovatif dalam kamus besar bahasa Indonesia 
ISSN. 2621-9832

JURNAL MathEdu (Mathematic Education Journal) http://journal.ipts.ac.id/index.php/MathEdu Vol. 4 No. 2 Juli 2021

dijelaskan sebagai memperkenalkan sesuatu yang baru, pembaruan (ciptaan baru). Guru dituntut untuk memiliki kemampuan memperkenalkan atau pembaharuan dan modifikasi dalam pembelajaran berupa alat dan media, metode teknis penyampaian materi kepada siswa agar tujuan pembelajaran dapat tercapai. Kreatif artinya memiliki kreativitas, kemampuan berkreasi dengan kecerdasan dan imajinasi (Nurjannah, 2020). Kritis dalam kamus besar bahasa Indonesia diartikan sebagai tidak cepat percaya, selalu berusaha mencari kesalahan atau kekeliruan, tajam dalam menganalisis. Guru dalam hal ini dapat menyaring semua informasi yang diterimanya, mampu menganalisis dengan tajam. (Hasan, 2019). Olehnya itu, guru harus mampu mengembangkan pembelajaran yang kreatif dan inovatif agar motivasi dan siswa dapat meningkat (Rahman et al., 2019).

Berkenaan dengan permasalahan yang diuraikan di atas, penggunaan gadget dan perangkat teknologi dapat diarahkan untuk digunakan pada hal-hal positif yang dapat membantu membuat pembelajaran menjadi lebih menarik. Penelitian dari Zabir (2018) menunjukkan bahwa dengan pemanfaatan teknologi, motivasi belajar siswa meningkat dan didorong untuk berpartisipasi secara aktif sehingga tercipta suasana yang kondusif untuk kegiatan belajar mengajar di kelas. Hal senada juga diungkapkan oleh Suripto, Fatmasari, dan Purwantiningsih (2010) bahwa guru dan siswa diuntungkan secara bersamaan dalam menggunakan fitur teknologi gamifikasi dalam pembelajaran dimana guru dapat lebih proaktif dan siswa dapat memperoleh sumber materi pelajaran yang tidak terbatas. Penggunaan gadget dan perangkat teknologi diintegrasikan ke dalam pembelajaran di kelas untuk menciptakan pengalaman belajar yang lebih menarik (Nugroho, et.al, 2019).

Adapun aplikasi gamifikasi daring yang diperkenalkan adalah Kahoot! dan Quizziz. Kahoot! merupakan aplikasi gamifikasi edukasi gratis yang menciptakan suasana belajar lebih menyenangkan. Kahoot! dapat diakses melalui web browser. Kahoot! diperkenalkan pertama kali pada tahun 2013 dan dirancang untuk pembelajaran sosial di mana siswa dapat berkumpul untuk belajar dan bermain Bersama (Solviana, 2020).

Aplikasi gamifikasi ini sangat sederhana namun sangat menarik. Guru, sebagai fasilitator, untuk pertama kalinya merancang soal, tes, review atau bahkan soal-soal sepele bahkan melalui Kahoot! Kemudian, guru dapat mempresentasikan permainan tersebut di kelas dengan menggunakan layar komputer atau smart-board. Siswa dapat bermain tanpa memiliki akun. Semua siswa dapat masuk melalui PIN yang disediakan dan bermain melalui gadget mereka baik secara individu maupun kelompok. Setiap jawaban yang dijawab dengan benar akan mendapatkan poin dan akan diurutkan berdasarkan perolehan skor dan kecepatan dalam menjawabnya. Prestasi ini akan dipajang di papan pemimpin yang mendorong siswa untuk berpikir cepat dan akurat (Solviana, 2020).

Beberapa penelitian yang telah dilakukan sebelumnya (Pede, 2017; Licorish, 2017; Plump dan LaRosa, 2017) menunjukkan bahwa aplikasi Kahoot! dapat memotivasi siswa dalam proses pembelajaran dan bahkan berhasil mengubah proses pembelajaran menjadi lebih menarik. Oleh karena itu, Kahoot! dapat menjadi solusi penggunaan gadget selama pembelajaran.

Aplikasi gamifikasi lainnya adalah Quizizz. Quizizz adalah aplikasi gratis berbasis gamification yang dapat dibuka melalui web browser. Melalui aplikasi ini, guru dapat menggabungkan pembelajaran, review dan evaluasi. Guru dapat terhubung dengan semua guru di dunia dan dapat mengakses kuis online yang dibuat oleh guru lain secara gratis. Oleh karena itu, guru bisa sekreatif mungkin di kelas dan tidak akan kehabisan ide (Solviana, 2020).

Pembelajaran berbasis game ini dapat dilakukan dalam mode 'live' di dalam kelas atau bisa juga diberikan sebagai pekerjaan rumah dalam mode 'pekerjaan rumah'. Ini sangat mungkin karena Quizizz menyediakan timer; kapan kuis akan dibuka dan kapan akan berakhir. Siswa hanya perlu diberikan PIN permainan dan mereka akan tetap bisa belajar dimanapun mereka berada. Siswa juga dapat mengerjakan kuis baik dalam bentuk kelompok maupun tugas individu. Keunggulan quizizz ada pada bagian proses yang disesuaikan dengan kecepatan siswa. Siswa tidak akan dinilai berdasarkan seberapa cepat mereka menjawab pertanyaan. Selain itu, skor dapat diunduh dalam dokumen excel untuk memudahkan guru dalam melakukan penilaian (Nugroho, et.al, 2019).

Zhao (2019) serta Mei, et.al (2018) menemukan bahwa Kuis berdampak positif terhadap proses pembelajaran di kelas dimana skor yang diperoleh lebih tinggi dan berpengaruh dalam peningkatan kerjasama antar siswa dalam kerja kelompok. Hal ini sangat positif, dan dianggap sebagai solusi penggunaan gadget di kelas.

\section{METODE PENELITIAN}

Penelitian ini adalah penelitian eksperimen yang menggunakan True Experimental Design dengan pretest dan posttest. Adapun sampel dalam penelitian ini adalah 27 siswa kelas VIIIB yang terdiri dari 16 siswa perempuan dan 11 siswa laki-laki. Teknik pengumpulan data dilakukan dengan dua acara yaitu tes 
ISSN. 2621-9832

JURNAL MathEdu (Mathematic Education Journal) http://journal.ipts.ac.id/index.php/MathEdu Vol. 4 No. 2 Juli 2021

dan observasi. Tes diberikan sebelum dan sesudah gamifikasi diberikan kepada sampel penelitian. Sedangkan observasi dimaksudkan untuk melihat bagaimana proses belajar siswa sebelum dan setelah gamifikasi diberikan. Adapun Teknik analisis data dilakukan dengan menggunakan uji paired sample t-test.

\section{HASIL DAN PEMBAHASAN}

Sebelum memberikan materi dengan gamifikasi, terlebih dahulu dilakukan uji pretest tentang materi yang diajarkan. Setelah melakukan uji pretest, siswa diberikan materi dengan menggunakan gamifikasi (Kahoot! dan Quizizz). Setelah gamifikasi diberikan, siswa kemudian diberikan uji posttest untuk melihat apakah ada peningkatam hasil belajar pada masing-masing siswa. Berikut hasil pretest dan posttest sampel penelitian.

Tabel 1. Hasil Pretest dan Posttest

\begin{tabular}{|c|c|c|}
\hline Nomor Urut Siswa & Pretest & Postest \\
\hline 1 & 55 & 78 \\
\hline 2 & 63 & 82 \\
\hline 3 & 57 & 76 \\
\hline 4 & 62 & 63 \\
\hline 5 & 63 & 77 \\
\hline 6 & 60 & 82 \\
\hline 7 & 67 & 85 \\
\hline 8 & 67 & 80 \\
\hline 9 & 78 & 97 \\
\hline 10 & 56 & 79 \\
\hline 11 & 83 & 95 \\
\hline 12 & 55 & 85 \\
\hline 13 & 69 & 80 \\
\hline 14 & 63 & 90 \\
\hline 15 & 67 & 75 \\
\hline 16 & 71 & 75 \\
\hline 17 & 65 & 80 \\
\hline 18 & 55 & 65 \\
\hline 19 & 59 & 75 \\
\hline 20 & 55 & 70 \\
\hline 21 & 67 & 80 \\
\hline 22 & 64 & 85 \\
\hline 23 & 54 & 85 \\
\hline 24 & 50 & 75 \\
\hline 25 & 70 & 85 \\
\hline 26 & 78 & 90 \\
\hline 27 & 65 & 75 \\
\hline
\end{tabular}

Sebelum melakukan uji paired sample t-test, sebelumnya dilakukan uji pendahuluan terlebih dahulu. Uji yang dilakukan adalah uji normalitas, untuk mengetahui apakah data pretest dan posttest siswa berdistribusi normal atau tidak. Berikut hasil uji normalitas dengan menggunakan SPSS 25.

Tabel 2. Hasil Uji Normalitas

One-Sample Kolmogorov-Smirnov Test

Unstandardized

Residual

\begin{tabular}{llr}
\hline $\mathrm{N}$ & & 27 \\
\hline Normal Parameters & Mean & .0000000 \\
\cline { 2 - 3 } & Std. Deviation & 6.56050905 \\
\hline \multirow{2}{*}{ Most Extreme Differences } & Absolute & .108 \\
\cline { 2 - 3 } & Positive & .059 \\
\cline { 2 - 3 } & Negative & -.108 \\
\hline Test Statistic & & .108 \\
\hline Asymp. Sig. (2-tailed) & & $.200^{\mathrm{c}, \mathrm{d}}$ \\
\hline
\end{tabular}

a. Test distribution is Normal. 
b. Calculated from data.

c. Lilliefors Significance Correction.

d. This is a lower bound of the true significance.

Dalam uji normalitas, data dikatakan berdistribusi normal jika nilai signifikasi lebih besar dari 0,05. Sebaliknya, data dikatakan tidak berdistribusi normal jika nilai signifikansi kurang dari 0,05 . Berdasarkan output di atas, diperoleh bahwa nilai Asymp Sig. (2-tailed) sebesar 0,200 lebih besar dari 0,05. Maka, sesuai dengan kaidah pengambilan keputusan, diperoleh kesimpulan bahwa data berdistribusi normal. Dengan demikian, asumsi atau persyaratan normalitas terpenuhi, sehingga dapat dilakukan uji paired sample t-test.

Selanjutnya dilakukan uji paired sample t-test untuk mengetahui keefektifan penggunaan gamifikasi. Berikut hasil output uji paired sample t-test dengan menggunakan SPSS.

Tabel 3. Hasil Uji Paired Samples Test

Paired Differences

\begin{tabular}{|c|c|c|c|c|c|c|c|c|c|}
\hline & \multicolumn{6}{|c|}{ Paired Differences } & \multirow[b]{3}{*}{$\mathrm{t}$} & \multirow[b]{3}{*}{$\mathrm{df}$} & \multirow{3}{*}{$\begin{array}{l}\text { Sig. }(2- \\
\text { tailed) }\end{array}$} \\
\hline & & \multirow[b]{2}{*}{ Mean } & \multirow{2}{*}{$\begin{array}{c}\text { Std. } \\
\text { Deviation }\end{array}$} & \multirow{2}{*}{$\begin{array}{l}\text { Std. Error } \\
\text { Mean }\end{array}$} & \multicolumn{2}{|c|}{$\begin{array}{l}95 \% \text { Confidence Interval } \\
\text { of the Difference }\end{array}$} & & & \\
\hline & & & & & Lower & Upper & & & \\
\hline Pair 1 & $\begin{array}{l}\text { Pretest - } \\
\text { Posttest }\end{array}$ & -16.51852 & 7.31894 & 1.40853 & -19.41380 & -13.62324 & -11.727 & 26 & .000 \\
\hline
\end{tabular}

Pada uji paired sample t-test, data dikatakan efektif jika nilai signifikasi kurang dari 0,05. Sebaliknya, data dikatakan tidak efektif jika nilai signifikasi lebih dari 0,05 (Irmayanti, Nurjannah \& Syarifuddin, 2021). Berdasarkan hasil output di atas diperoleh bahwa nilai mean sebesar -16,51852. Mean bernilai negative artinya ada peningkatan hasil belajar siswa dengan rata-rata 16,51852. Nilai signifikansi sebesar 0,000 dimana nilai ini kurang dari 0,05. Sehingga, berdasarkan kaidah pengambilan keputusan diperoleh bahwa ada perbedaan hasil belajar sebelum dan sesudah dilakukannya gamifikasi. Dengan kata lain, pemberian gamifikasi efektif dalam pembelajaran matematika.

Berdasarkan hasil analisis di atas diperoleh bahwa pemberian gamifikasi baik itu Kahoot! dan Quizizz dapat meningkatkan hasil belajar siswa. Karena Kahoot! dan Quizizz membuat siswa lebih bersemangat dan tidak jenuh terhadap proses pembelajaran (Daryanes \& Ririen, 2020). Kahoot! dan Quizizz juga mampu meningkatkan motivasi belajar siswa karena memberikan warna baru pada proses pembelajaran (Citra \& Rosy, 2020). Pemberian materi secara terus menerus tanpa diselingi dengan game akan membuat siswa merasa malas dan bosan sehingga gamifikasi seperti ini memang sangat dibutuhkan oleh siswa.

\section{KESIMPULAN}

Terdapat peningkatan hasil belajar sebelum dan sesudah pemberian gamifikasi (Kahoot! dan Quizizz) sehingga dapat disimpulkan bahwa pemberian gamifikasi efektif dalam pembelajaran matematika. Gamifikasi seperti Kahoot! dan Quizizz sangat disarankan untuk guru-guru sehingga dapat mendongkrak semangat belajar siswa dan menghilangkan kejenuhan siswa dalam proses pembelajaran. Gamifikasi juga dapat memberikan warna baru pada proses pembelajaran karena proses pembelajaran menjadi tidak monoton.

\section{REFERENSI}

Citra, C. A., \& Rosy, B. (2020). Keefektifan Penggunaan Media Pembelajaran Berbasis Game Edukasi Quizizz Terhadap Hasil Belajar Teknologi Perkantoran Siswa Kelas X SMK Ketintang Surabaya. Jurnal Pendidikan Administrasi Perkantoran (JPAP), 8, 261-272. https://journal.unesa.ac.id/index.php/jpap/article/view/8242/4081

Darmawiguna, I.G.M., Satyadiputra,G.S., Pradnyana, G.A., \& Pradnyana, I.M.A. (2019). Pelatihan Implementasi Gamifikasi Dalam Pembelajaran Dengan Platform Kahoot Bagi Guru-guru Di SMK Negeri 1 Nusa Penida. Prosiding SENADIMAS Ke-4, 967-972.

Daryanes, F., \& Ririen, D. (2020). Efektivitas Penggunaan Aplikasi Kahoot Sebagai Alat Evaluasi pada Mahasiswa. Journal of Natural Science and Integration, 3(2), 172. https://doi.org/10.24014/jnsi.v3i2.9283

Hasan, Y. (2019). Pentingnya Inovasi Guru Dalam Proses Kegiatan Belajar Dan Mengajar. Seminar Nasional Pendidikan. Palembang.

Irmayanti,I., Nurjannah, N., Syarifuddin, S. (2021). Statistika Dasar. Yogyakarta: Pena Persada. 
Licorish, S., Owen, H., Daniel, B., \& George, J. (2018). Students' perception of Kahoot!'s influence on teaching and learning.Research and Practice in Technology Enhanced Learning,13(1).

Mei, S., Ju, S., \& Adam, Z. (2018). Implementing Quizizz as Game Based Learning in the Arabic Classroom.European Journal of Social Sciences Education and Research, 12(1), 208.

Nugroho, D.Y., Situmorang, K., Tahulending, P.S., Maxmila, M., \& Rumerung, C.L. (2019). Pemanfaatan Teknologi dalam Pendidikan: Penggunaan Fitur Gamifikasi Daring Di Ypk Penabur Bandarlampung. Prosiding PKM-CSR, Vol. 2, 1-9.

Pede, J., (2017). The effects of the online game kahoot on science vocabulary acquisition. Master Thesis.Rowan University.

Plump, C., \& LaRosa, J. (2017). Using Kahoot! in the Classroom to Create Engagement and Active Learning: A Game-Based Technology Solution for eLearning Novices.Management Teaching Review,2(2), 151-158. doi: 10.1177/2379298116689783.

Rahman, H., Nurjannah, N., \& Syarifuddin, S. (2019). Aplikasi Expert System Berbasis Fuzzy logic untuk Mendiagnosa Gaya Belajar Dominan Mahasiswa Tadris Matematika IAIM Sinjai. JTAM | Jurnal Teori Dan Aplikasi Matematika, 3(2), 143. https://doi.org/10.31764/jtam.v3i2.1044

Solviana, M.D. (2020). Pemanfaatan Teknologi Pendidikan Di Masa Pandemi Covid-19: Penggunaan Fitur Gamifikasi Daring Di Universitas Muhammadiyah Pringsewu Lampung. Al-Jahiz: Journal of Biology Education Research 1(1), 1-14.

Suripto,.Fatmasari, R. Purwantiningsih, A. (2010).Penggunaan Teknologi Informasi Komunikasi dan Dampaknya Dalam Dunia Pendidikan. Makalah Seminar: Citizen Journalism dan Keterbukaan Informasi Publik untuk Semua, p.1-11

Zabir, A. (2010). Pengaruh Pemanfaatan Teknologi Pembelaran Terhadap Motivasi Belajar Siswa SMPN 1 Lanrisang Kabupaten Pinrang. Eprints.unm.ac.id.

Zhao, F., (2019). Using Quizizz to Integrate Fun Multiplayer Activity in the Accounting Classroom. International Journal of Higher Education. Vol. 8, No. 1; 2019. doi:10.5430/ijhe.v8n1p37. 